\title{
Effects of Ultrahigh Temperature Pasteurization on the Liquid Components and Functional Properties of Stored Liquid Whole Eggs
}

\author{
Tong Liu $\left(\mathbb{D},{ }^{1}\right.$ Bo Lv $\mathbb{D}^{1},{ }^{1}$ Weixuan Zhao $\left(\mathbb{D},{ }^{2}\right.$ Yuhua Wang $\left(\mathbb{D},{ }^{1}\right.$ Chunhong Piao $\left(\mathbb{D},{ }^{1}\right.$ \\ Weichang Dai $\mathbb{D}$, ${ }^{1}$ Yaohui Hu $\mathbb{D}^{1},{ }^{1}$ Junmei Liu $\mathbb{D}^{1},{ }^{1}$ Hansong $Y u\left(\mathbb{D},{ }^{1}\right.$ and Fengjie Sun $\mathbb{D}^{3}$ \\ ${ }^{1}$ College of Food Science and Engineering, Jilin Agricultural University, Changchun 130118, China \\ ${ }^{2}$ Department of Neurology, The First Hospital of Jilin University, Changchun 130021, China \\ ${ }^{3}$ School of Science and Technology, Georgia Gwinnett College, Lawrenceville, GA 30043, USA
}

Correspondence should be addressed to Hansong Yu; yuhansong@jlau.edu.cn and Fengjie Sun; fsun@ggc.edu

Tong Liu, Bo Lv, and Weixuan Zhao contributed equally to this work.

Received 10 October 2019; Accepted 18 December 2019; Published 11 January 2020

Academic Editor: Ashok Nadda

Copyright (c) 2020 Tong Liu et al. This is an open access article distributed under the Creative Commons Attribution License, which permits unrestricted use, distribution, and reproduction in any medium, provided the original work is properly cited.

Ultrahigh temperature (UHT) pasteurization is often used to sterilize liquid whole eggs in egg processing enterprises in China. Although this treatment generates satisfactory sterilization effect, there are few studies on the processing characteristics and physical and chemical properties of the liquid whole eggs treated by UHT pasteurization. We compared the physical and chemical properties (i.e., foaming ability and stability, emulsification ability and stability, viscosity, thiol content, gel strength, and color) of unsterilized eggs and liquid whole eggs pasteurized with UHT over five weeks of storage. The emulsifying properties of sterilized liquid whole eggs were initially low and decreased further with the storage time. The emulsification stability index of UHTpasteurized liquid whole eggs was higher than that of unsterilized eggs and increased by $21.9 \%$, from 7.850 to 9.567 . The foaming ability of UHT-pasteurized and unsterilized liquid whole eggs increased by $33.38 \%$ and $15.48 \%$, respectively. The viscosity, gel strength, and soluble protein content were higher in UHT-pasteurized liquid whole eggs than those in unsterilized liquid whole eggs and increased further with storage time. Our results demonstrate that UHT pasteurization preserves and improves the processing characteristics and shelf life of liquid whole eggs.

\section{Introduction}

Eggs are a kind of food with comprehensive nutrition and balanced nutrient proportions [1]. Eggs are rich in proteins with a biological value of $94 \%$, generally known as standard proteins by nutritionists. Eggs not only provide a balanced protein contents for the human body but also contain rich nutrients such as lipids, carbohydrates, minerals, and vitamins, which play important roles in the growth and development of infants, children, and adolescents [2, 3]. Besides their high nutritional values, eggs also have many important functional properties, such as coagulation, emulsification, foaming, and thermodynamics. These functional characteristics make eggs widely used to help improve color, aroma, taste, and nutritional values in various foods, which cannot be simply replaced by any other additives [4-6].

Liquid whole eggs refer to the products that the eggshells are removed and the liquid portions are processed and packed to replace the fresh eggs. To make liquid whole eggs effectively solves the problems of being fragile, difficult transportation, and difficult storage generated by the fresh eggs. They can also meet various technological requirements according to the different nutrient compositions and functional characteristics of egg white and yolk. More importantly, by efficient packaging, liquid whole eggs could avoid the contamination by bacteria and viruses in the environments during storage and transportation [7]. Since the 1990's, due to the food poisoning incidents caused by 
Salmonella in fresh eggs, strict regulations have been enacted to prohibit shelled eggs from entering food factory applications in the EU countries, the United States, and Japan [8]. Furthermore, it is required to use sterilized egg products in foods and beverages in these countries [8]. The pasteurized liquid whole eggs account for $30-40 \%$ of egg production in the United States, Japan, Europe, and Australia. In contrast, the sterilized eggs are only less than $1 \%$ in China [9].

Pasteurization is the most commonly used sterilization method for liquid whole eggs worldwide, though there are slightly different requirements in sterilization temperature and time in different countries $[10,11]$. However, because proteins are sensitive to temperature, pasteurization causes a negative impact on egg processing, physical and chemical properties, nutritional values, and sensory properties (e.g., color and texture) [12]. Studies have been focused on the nonthermal sterilization of liquid whole eggs [13-17]. For example, de Souza and Fernández [18] sterilized liquid whole eggs by UV-C method, which significantly inactivated Salmonella enteritidis. Specifically, S. enteritidis in the liquid whole eggs decreased by about four log values, while the effect of low-dose UV light resulted in a darker color of the liquid whole egg [18]. de Souza et al. [19] reported that the flow behaviors were not changed in UV-C-treated egg white, whole egg, and egg yolk, and the relevant protein denaturation or aggregation was not significant. Monfort et al. [20] treated liquid the whole eggs with both high-pressure homogenization and pasteurization. Their results showed that the number of $E$. coli in liquid whole eggs was reduced by about five logarithms, while the processing characteristics maintained as similar to those of untreated liquid whole eggs. Hermawan et al. [21] demonstrated the bactericidal effect on Salmonella in the liquid whole eggs by the pulsed electric field (PEF) technology. Geveke et al. [22] treated liquid whole eggs with both radio frequency $(\mathrm{RF})$ heating and pasteurization to show that the number of $E$. coli in liquid whole eggs was reduced by more than six logarithms, while the number of $E$. coli was reduced only slightly more than one logarithmic value in the liquid whole eggs treated with both strong PEF and pasteurization [23]. In general, these studies have shown common limitations in industrial production, e.g., the small amount of liquid whole eggs treated and the high cost of treatment, subsequently not meeting the requirements of industrial production. Further studies are necessary to make significant improvement in these areas to find sterilization methods with low cost and high efficiency in reducing the bacteria in the liquid whole eggs.

UHT pasteurization using high temperature $\left(135^{\circ} \mathrm{C}\right.$ or higher) in short time (2-3 seconds) has been used to sterilize liquid whole eggs in egg processing enterprises in China [9]. This approach has showed satisfactory sterilization effect and to reduce the negative impact of pasteurization on all aspects of egg characteristics. However, studies on the processing characteristics and physicochemical properties of liquid whole eggs treated by UHT pasteurization are sparse. In the present study, we compared the physical and chemical properties (i.e., foaming ability and stability, emulsification and emulsion stability, viscosity, thiol content, gel strength, and color) of unsterilized eggs and UHT-pasteurized liquid whole eggs over five weeks of storage. Our results showed that UHT pasteurization preserves and improves the processing characteristics and potentially increases the shelf life of liquid whole eggs, demonstrating the feasibility and advantages of using UHT pasteurization in processing the liquid whole eggs in comparison with the conventional methods of sterilization.

\section{Materials and Methods}

2.1. Materials and Instruments. UHT-pasteurized $\left(135^{\circ} \mathrm{C}\right.$ or higher treated for 2-3 seconds) liquid chicken eggs were purchased from Jilin Jinyi Egg Co. (Liaoyuan, China). A water bath (HW.SY Changfeng Instrument Co., Beijing, China), Elias Infinite M200 NanoQuant (Tecan, Switzerland), viscometer (NDJ-4; Scientific Instrument Co., Shanghai, China), high-speed emulsification instrument (FA25; FLUKO Equipment Co., Shanghai, China), and texture analyzer (TA-XT Plus; Stable MicroSystem Co., Surrey, UK) were used in this study. All chemicals and reagents used in this study were of analytical grade.

2.2. Evaluation of Foaming Ability and Stability. Foaming ability and foam stability were performed according to the methods reported previously [24]. The mixture of liquid whole eggs $(40 \mathrm{ml})$ and water $(800 \mathrm{ml})$ was emulsified at $10,000 \mathrm{rpm}$ for $1 \mathrm{~min}$. For foaming ability analysis, volume ( $V 1)$ was recorded immediately after homogenization; for foam stability analysis, volume (V2) was recorded after $30 \mathrm{~min}$ of continuous homogenization. Foaming ability and foam stability were calculated using the following equations:

$$
\begin{gathered}
\text { Foaming ability }(\%)=\left[\frac{V 1(\mathrm{ml})}{840}\right] \times 100, \\
\text { Foaming stability }(\%)=\left[\frac{V 2(\mathrm{ml})}{840}\right] \times 100 .
\end{gathered}
$$

2.3. Evaluation of Emulsification Ability and Emulsification Stability. The analyses of emulsification activity and emulsification stability were based on the methods reported previously with minor modifications [25]. Saline $(2.92 \%$ of $\mathrm{NaCl})$ and detergent ( $0.1 \%$ sodium dodecyl sulfate (SDS)) solutions were prepared in double-distilled water. Liquid whole eggs $(2.5 \mathrm{~g})$ were mixed with $500 \mathrm{ml}$ saline solution. The mixture $(180 \mathrm{ml})$ was combined with $120 \mathrm{ml}$ soybean oil and emulsified for $1 \mathrm{~min}$. Then, $0.3 \mathrm{ml}$ of the mixed emulsion was collected three times ( 0,3 , and $6 \mathrm{~min})$, and each sample was mixed with $6 \mathrm{ml}$ SDS solution. Absorbance was measured at $500 \mathrm{~nm}$ with SDS solution used as a standard. The emulsification activity index (EAI) was expressed as $A_{0}$, which is the absorbance at $0 \mathrm{~min}$, while the emulsification stability index (ESI) was calculated with the following equation:

$$
\mathrm{ESI}=\frac{A_{0} \times \Delta T}{\Delta A},
$$


where $\Delta T$ is the time interval ( $\min ), \Delta A$ is the difference in absorbance between the 0 - and 3-min time points, and $A_{0}$ is the absorbance at $0 \mathrm{~min}$.

2.4. Measurement of Liquid Whole Egg Viscosity. The viscosity of the liquid whole eggs was measured according to the method of Sánchez-Gimeno et al. [26]. The viscosity of liquid whole eggs was determined by applying various rotors and speeds. The sample with the highest percentage viscosity was selected for further analysis. Liquid whole eggs $(500 \mathrm{ml})$ were added to the rotary viscometer, and the final viscosity of the liquid whole eggs was measured by equilibrating rotor $\# 2$ at room temperature for $10 \mathrm{~min}$, with rotating speeds of 30 and $60 \mathrm{rpm}$, respectively.

2.5. Analysis of Physical Properties of Egg Gel. Egg gels were prepared as described previously [27]. To determine the physical properties of the egg gel, $40 \mathrm{ml}$ of egg gel was collected in a $50-\mathrm{ml}$ tube and incubated for $30 \mathrm{~min}$ in a water bath $\left(90^{\circ} \mathrm{C}\right)$. The tubes were immediately cooled for $15 \mathrm{~min}$ in an ice water bath and stored at $4^{\circ} \mathrm{C}$ for $24 \mathrm{~h}$ in order to equilibrate the gel. The gel was then re-equilibrated at room temperature, and its hardness was determined with probes (type: P $0.5 \mathrm{~S}$ ), with a pretest speed of $5.0 \mathrm{~mm} / \mathrm{s}$, test speed of $2.0 \mathrm{~mm} / \mathrm{s}$, and posttest speed of $5.0 \mathrm{~mm} / \mathrm{s}$.

2.6. Egg Surface Thiol Content. Determination of thiol content on egg surface was performed according to the methods reported previously [28]. The liquid whole eggs $(0.2 \mathrm{~g})$ were diluted to $10 \mathrm{mg} / \mathrm{ml}$ in Tris glycine buffer (0.1 mol/l, $\mathrm{pH} 8.0)$. Then, $1 \mathrm{ml}$ of diluted liquid whole egg and $3 \mathrm{ml}$ of buffer were mixed with $40 \mu \mathrm{l}$ of $5,5^{\prime}$-dithio bis-2nitrobenzoic acid (DTNB) solution, followed by incubation in a water bath $\left(25^{\circ} \mathrm{C}\right)$ for $30 \mathrm{~min}$. The absorbance was measured at $412 \mathrm{~nm}$ with Ellman reagent used as a blank. Turbidity was determined by adding samples instead of Ellman reagent. The thiol content was calculated using the equation SH $(\mu \mathrm{mol} / \mathrm{g})=\left(75.53 \times A_{412} \times D\right) / C$, where $A_{412}$ is the difference between the absorbance of the samples with DTNB and the samples without DTNB at $412 \mathrm{~nm}, C$ is the concentration of liquid whole eggs, and $D$ is the dilution factor for the sample.

2.7. Color Evaluation. Color parameters were determined using a colorimeter according to Koç et al. [5]. Each sample was measured nine times to determine the Lightness ( $\mathrm{L} *$ ) index, which represents the lightness of a sample where red and green contents are represented by positive and negative values of a* (redness), respectively, while yellow and blue contents are indicated by positive and negative values of $b *$ (yellowness), respectively.

2.8. Determination of Soluble Protein Content in Liquid Whole Eggs. Soluble protein contents were measured as described by Hamid-Samimi et al. [29]. Liquid whole eggs were diluted with physiological saline at a ratio of $1: 9$ and then centrifuged at $10,000 \mathrm{rpm}$ for $10 \mathrm{~min}$. The supernatant was diluted with $1 \%$ of the egg homogenate by adding nine times the volume of physiological saline as a test solution. The test solution $(1 \mathrm{ml})$ was added to a test tube with $5 \mathrm{ml}$ of Coomassie brilliant blue solution followed by incubation for $5 \mathrm{~min}$. The absorbance was measured at $595 \mathrm{~nm}$, and a standard curve was generated to determine the soluble protein contents.

2.9. Statistical Analysis. All experiments were performed three times, and data were shown as mean \pm standard deviation. Differences between groups of samples were evaluated by analysis of variance (ANOVA) using SPSS v.18.0 software (SPSS Inc., Chicago, IL, USA). Significant differences among treatments were analyzed with Duncan's multiple range test $(P<0.05)$.

\section{Results and Discussion}

3.1. Foaming Ability and Stability of UHT-Pasteurized and Unsterilized Liquid Whole Eggs. Foaming ability is a desirable property for eggs mainly determined by the content and interactions of egg white proteins but inhibited by egg yolk proteins [30]. In our study, the foaming ability of both unsterilized and UHT-pasteurized liquid whole eggs gradually decreased over time during the first week of storage (Figure 1(a)). However, the foaming ability started to increase in the second and the third weeks of storage for the UHT-pasteurized and unsterilized liquid whole eggs, respectively, with the latter decreasing thereafter. These results showed that the foaming ability varied with storage time. For example, in the first week, the foaming ability of UHTpasteurized liquid whole eggs $(0.168)$ was lower than that of unsterilized liquid whole eggs (0.18), with the former showing a higher foaming index than the latter. For the next four weeks of storage, the UHT-pasteurized liquid whole eggs showed higher foaming ability than that of the unsterilized eggs with an overall decreasing trend in foaming ability (Figure 1(a)). We speculate that the decline in foaming ability over time may be attributable to the formation of insoluble macromolecular aggregates that crosslink and polymerize with egg proteins, a phenomenon observed previously [31]. These macromolecules may not expand or be readily adsorbed at the gas-water interface, leading to the reduced foaming ability.

The results showed that the foam stability of UHTpasteurized liquid whole eggs first increased in the first three weeks and then decreased during the next two weeks over time (Figure 1(b)), with stability index differing significantly between the UHT-pasteurized and unsterilized liquid whole eggs during weeks 1,2 , and 5 . The foam stability index of UHT-pasteurized liquid whole eggs reached the highest during the third week of storage (0.913). The unsterilized eggs showed initially increased foam stability but then decreased in the third week and reached the highest value during week 5 (0.89). These results showed that the foaming stability varied with storage time except during the first two weeks. The foam stability of UHT-pasteurized liquid whole 


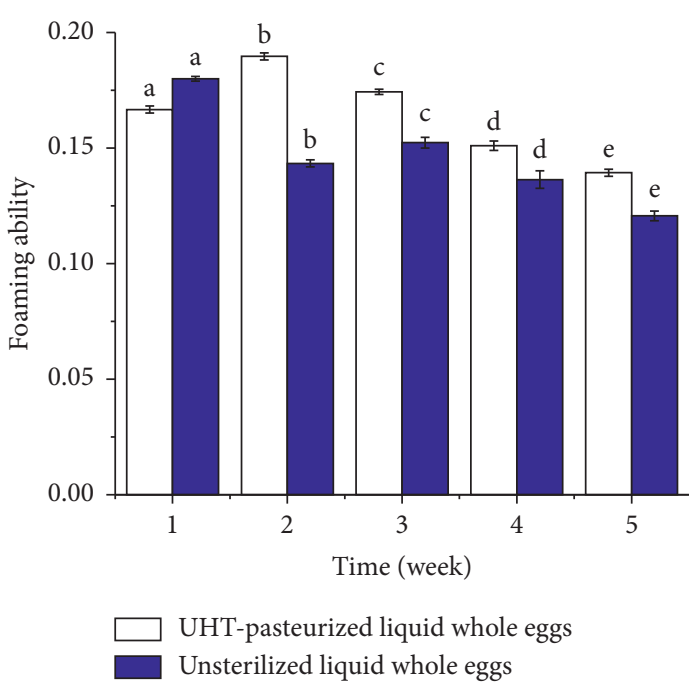

(a)

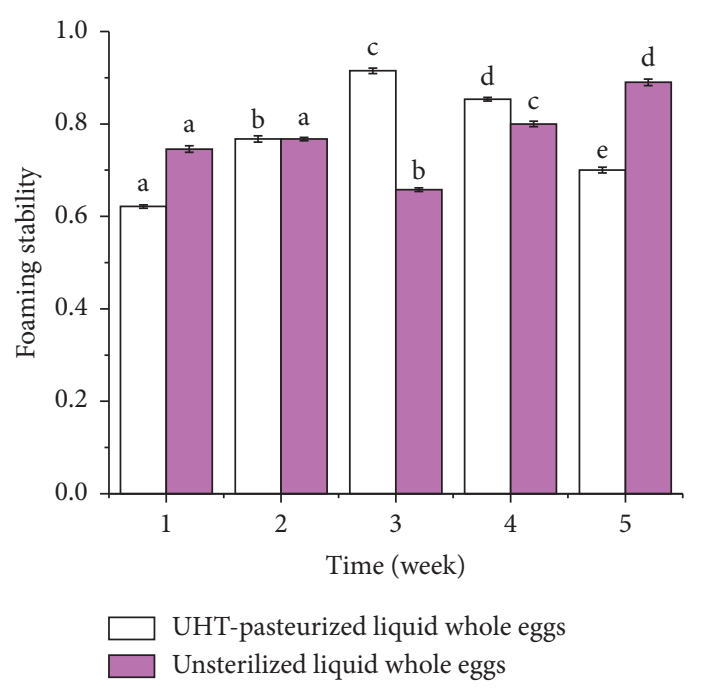

(b)

FIGURE 1: Foaming ability (a) and foaming stability (b) of unsterilized and UHT-pasteurized liquid whole eggs. Values showing statistically significant differences in foaming ability and stability indices are indicated with different letters $a, b, c, d$, or e $(P<0.05)$.

eggs was higher than that of unsterilized eggs during weeks 2 to 4 of storage, but the reverse was true during week 5 , possibly because the denaturation of egg proteins exposed their thiol and hydrophobic groups, resulting in polarization and formation of large molecular aggregates due to noncovalent bonding [32]. This presumably decreases the stability of the air-water interface, leading to the loss of foam stability.

Our results showed that the UHT-pasteurized liquid whole eggs maintained substantially the similar foaming ability and foaming stability as the untreated eggs. The similar results showing the maintained foaming ability and foaming stability in treated liquid whole eggs were also reported by $\mathrm{Ma}$ et al. [33], who sterilized the liquid whole eggs with UV-C to reveal the improved foaming ability and stability of the eggs. These results are also supported by the consumer survey studies conducted by de Souza and Fernández [34]. In contrast, studies have shown that treating eggs with the conventional pasteurization significantly reduces their foaming ability and stability [35].

\subsection{Emulsification Ability and Stability of UHT-Pasteurized} and Unsterilized Liquid Whole Eggs. Egg white proteins exhibit poor emulsification due to their globular structures and low hydrophobicity, while egg yolk shows evident emulsification properties [36]. Our results showed that the emulsification ability of both UHT-pasteurized and unsterilized liquid whole eggs decreased (from 0.806 to 0.439 and from 1.101 to 0.514 , respectively) over the five weeks of storage, with the former showing reduced emulsification ability (Figure 2(a)). The emulsification stability of UHTpasteurized and unsterilized liquid whole eggs increased during the third week of storage from 7.403 to 9.779 and from 7.073 to 7.962 , respectively (Figure 2(b)), with the UHT-pasteurized liquid whole eggs showing the higher ESI than the unsterilized eggs. Previous studies showed that the pulsed electric fields (PEF) treatments with $30 \mathrm{kV} / \mathrm{cm}$ for $800 \mu \mathrm{s}$ at $40^{\circ} \mathrm{C}$ significantly increased the emulsifying capacity and stability of liquid whole eggs by $6.4 \%$ and $11.3 \%$, respectively [25]. The improved emulsification ability and stability were also reported in the liquid whole eggs treated in a coiled tube UV-C reactor in comparison with the unsterilized eggs [19].

Studies have shown that the emulsification of the liquid whole eggs is affected by the proteins in egg yolks and egg white and the $\mathrm{pH}$ values during the storage [37]. Specifically, these proteins influence the emulsification of the liquid whole eggs by their structures and surface hydrophobicity, while the $\mathrm{pH}$ values affect the emulsification by changing the absorption at the oil-water interface. The $\mathrm{pH}$ values increased first and then decreased rapidly during the storage when the number of microorganisms increased and the proteins denatured, causing the decrease of the emulsifying ability in our UHT-pasteurized liquid whole eggs. Furthermore, studies have also shown that as the $\mathrm{pH}$ values increased, the emulsification ability decreased evidently, while the emulsification stability increased gradually [38]. Our result showed that as the storage time increased in the first three weeks, the emulsification ability of the UHTpasteurized liquid whole eggs decreased, while emulsification stability of the UHT-pasteurized liquid whole eggs increased (Figure 2). As the time of storage is further prolonged, proteins in the liquid whole eggs increased the degree of denaturation to ultimately becoming completely denatured and formed the polymers with other substances, causing the decreased emulsifying ability. Furthermore, the hydrophobic groups in proteins were exposed and aggregated to increase the degree of flocculation, subsequently causing the decreased emulsification stability.

3.3. Viscosity of UHT-Pasteurized and Unsterilized Liquid Whole Eggs. Previous studies demonstrated that the eggs 


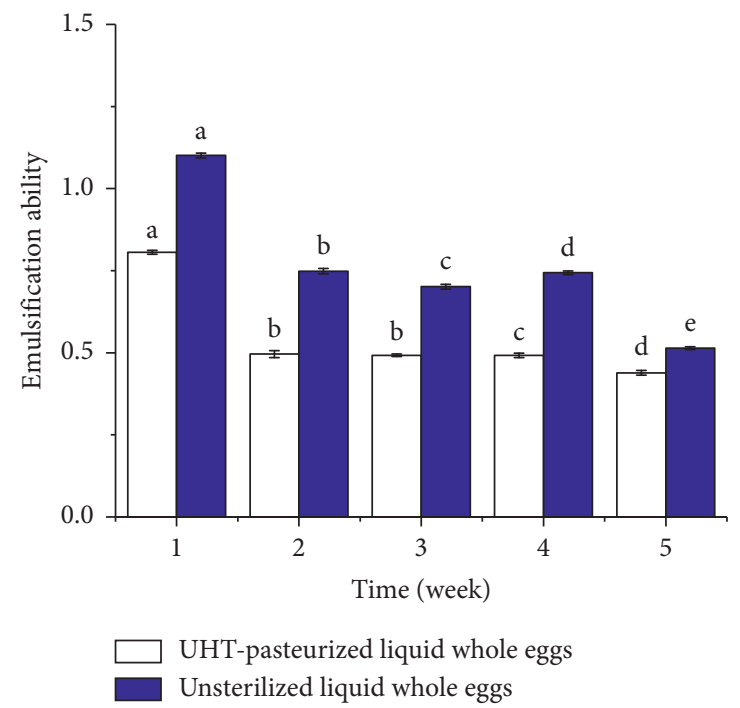

(a)

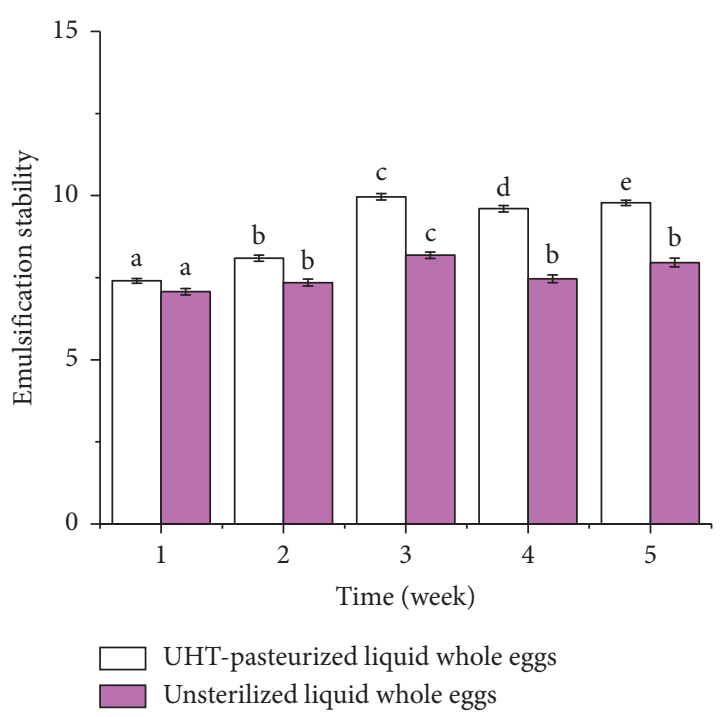

(b)

FIGURE 2: Emulsification ability (a) and stability (b) of UHT-pasteurized and unsterilized liquid whole eggs. Values showing statistically significant difference in emulsification ability and stability are indicated with different letters $\mathrm{a}, \mathrm{b}, \mathrm{c}, \mathrm{d}$, or e $(P<0.05)$.

treated by traditional pasteurization, PEF sterilization, and other technologies showed increased viscosity in comparison with those of unsterilized eggs $[10,21,29]$. Our results showed that the viscosity differed significantly between UHT-pasteurized and unsterilized liquid whole eggs $(P<0.05)$. In the third week of storage, the viscosity of UHTpasteurized egg was low $(14.0 \mathrm{mPa} \cdot \mathrm{s})$ but increased to $26.0 \mathrm{mPa} \cdot \mathrm{s}$ by week 5 (Table 1), while the viscosity of unsterilized liquid whole eggs initially increased to the highest value of $32.6 \mathrm{mPa}$.s in three weeks and then decreased to the lowest value of $20.0 \mathrm{mPa} \cdot \mathrm{s}$ by week 5 . The viscosity of unsterilized eggs decreased during weeks $3-5$ of storage, while the UHT-pasteurized liquid whole eggs showed increasing trend in their viscosity. These results indicated that the UHT pasteurization could potentially extend the storage time of liquid whole eggs in comparison with the unsterilized liquid whole eggs.

Phosphoproteins play an important role in maintaining egg protein structure. With the extended storage time, the structure of proteins in eggs is denatured and the protein mixtures become watery. The viscosity of unsterilized liquid whole eggs decreased as a result of the changes in protein structure and microbe-induced protein degradation causing the decrease in cross-linkage among proteins. In our study, the viscosity of UHT-pasteurized liquid whole eggs increased as the proteins in the eggs were slowly denatured due to the decreased microbial load. Therefore, the normal crosslinkage and polymerization between proteins are preserved and protein structures are maintained by pasteurization [39].

3.4. Thiol Contents of UHT-Pasteurized and Unsterilized Liquid Whole Eggs. Changes in thiol content reflects the changes in the protein contents and structures in the liquid whole eggs [32]. In our study, the thiol contents of UHT- pasteurized liquid whole eggs declined to the lowest concentration of $4.75 \mu \mathrm{mol} / \mathrm{mg}$ during week 2 of storage and then increased to the highest concentration of $12 \mu \mathrm{mol} / \mathrm{mg}$ during week 5 (Figure 3), while the thiol contents in the unsterilized liquid whole eggs reached the highest concentration of $12.5 \mu \mathrm{mol} / \mathrm{mg}$ in the first week of storage and decreased to the lowest of $6 \mu \mathrm{mol} / \mathrm{mg}$ at week 4 .

The high temperatures $\left(135^{\circ} \mathrm{C}\right.$ or higher) used in the UHT sterilization process cause the denaturation of proteins in eggs, particularly the ovalbumin and ovotransferrin, exposing the free sulfhydryl groups (thiol) inside the proteins and leading to an increase in sulfhydryl content [40]. However, the protein structure remains mostly intact if the treatment of pasteurization is short (i.e., 2-3 seconds), allowing some proteins to repolymerize, consequently decreasing the sulfhydryl content. Degradation and denaturation of proteins in liquid whole eggs take place with the prolonged storage time and the interactions between these two processes increase the sulfhydryl content. The unsterilized eggs are infected easily by microorganisms during storage. In our study, we speculate that some proteins became denatured during week 1 of storage, exposing the interior sulfhydryl groups and increasing the sulfhydryl content in the liquid whole eggs. However, the exposed sulfhydryl groups were later oxidized to form disulfide bonds or crosslinks, leading to a decrease in sulfhydryl content. Furthermore, the increased interactions between denatured proteins may also contribute to the reduction of the sulfhydryl content.

3.5. Gel Strength of UHT-Pasteurized and Unsterilized Liquid Whole Eggs. The strength of UHT-pasteurized liquid whole eggs gradually decreased over time (Table 2). In the first week of storage, the UHT-pasteurized liquid whole eggs showed the highest gel strength $\left(1504.39 \mathrm{~g} / \mathrm{cm}^{2}\right)$ and was 
TABLE 1: Viscosity of UHT-pasteurized and unsterilized liquid whole eggs. Values showing statistically significant difference in each group of eggs are indicated with different superscript letters a, b, c, or $\mathrm{d}(P<0.05)$.

\begin{tabular}{lcc}
\hline Storage time (week) & Unsterilized liquid whole eggs $(\mathrm{mPa} \cdot \mathrm{s})$ & UHT-pasteurized liquid whole eggs $(\mathrm{mPa} \cdot \mathrm{s})$ \\
\hline 1 & $26.0 \pm 0.00^{\mathrm{b}}$ & $14.2 \pm 0.57^{\mathrm{ab}}$ \\
2 & $30.0 \pm 0.50^{\mathrm{c}}$ & $15.0 \pm 0.00^{\mathrm{b}}$ \\
3 & $32.6 \pm 0.57^{\mathrm{d}}$ & $14.0 \pm 0.00^{\mathrm{a}}$ \\
4 & $25.0 \pm 0.00^{\mathrm{b}}$ & $17.0 \pm 0.50^{\mathrm{c}}$ \\
5 & $20.0 \pm 0.50^{\mathrm{a}}$ & $26.0 \pm 0.50^{\mathrm{d}}$ \\
\hline
\end{tabular}

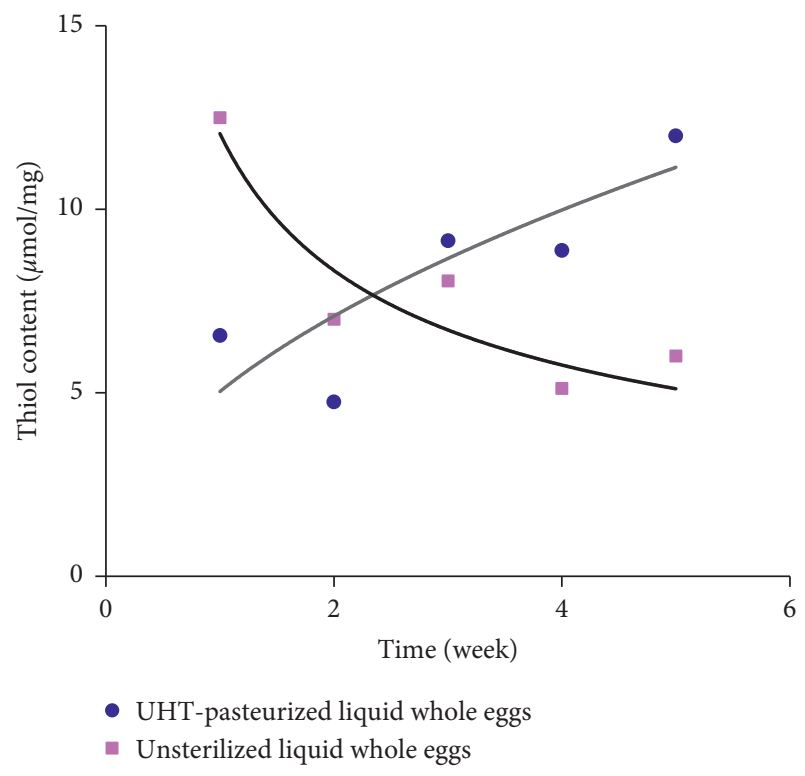

FIgURE 3: The thiol content of UHT-pasteurized and unsterilized liquid whole eggs.

higher than that of the unsterilized eggs $\left(1345.27 \mathrm{~g} / \mathrm{cm}^{2}\right)$. The gel strength of unsterilized eggs increased slightly reaching the highest gel strength $\left(1348.14 \mathrm{~g} / \mathrm{cm}^{2}\right)$ during the second week of storage then decreased gradually for the next three weeks of storage. These results showed that the gel strength of UHT-pasteurized eggs was higher than that of unsterilized eggs, indicating that the changes in the proteins of the eggs occurred more slowly in the former than in the latter and suggesting that the UHT pasteurization has the potential of increasing the shelf life of liquid whole eggs. Similar results were also reported by Monfort et al. [35]. Specifically, the liquid whole eggs showed significantly increased gel strength when treated with PEF and then heated in the presence of triethyl citrate. Furthermore, the increased gel strength of the sterilized eggs helped improve the mouthfeel of liquid whole egg-derived products [10].

Liquid whole eggs solidify as they are heated. This coagulation process is an important property of proteins. The thermal gelation process includes various physical and chemical interactions. Yolk protein and LDL in egg yolk plasma play an important role in yolk gelation [41]. Physical and chemical interactions mainly occur between denatured proteins that form polymers with other proteins through crosslinking between sulfhydryl groups [42], which contributes to the protein gel formation [43]. Therefore, in our study, we speculate that the higher gel strength of UHT- pasteurized liquid whole eggs in comparison to the unsterilized eggs was due to the pasteurization inducing the unfolding of protein structure to expose the interior sulfhydryl groups and allow the crosslinking of disulfide bonds, which in turn increases the gel strength.

3.6. Analysis of Liquid Whole Egg Color. The chroma values of both the UHT-pasteurized and unsterilized liquid whole eggs increased initially and then decreased over the five weeks of storage (Table 3). Both the UHT-pasteurized and unsterilized liquid whole eggs reached their highest chroma values during week 2 of 66.1 and 67.7, respectively, while reaching their lowest at week 5 of 63.3 and 63.4, respectively. The UHT-pasteurized liquid whole eggs showed the highest value of their yellowness index (43.96) during week 2 of storage. The yellowness index value of the UHT-pasteurized eggs was lower than that of the unsterilized eggs during the first week of storage with 41.62 and 46.32, respectively. Similar results were reported by Monfort et al. [35], demonstrating that the color of sterilized eggs showed lower redness and yellowness values than those of untreated eggs. However, in the remaining weeks 2-5, the yellowness index values of UHT-pasteurized eggs were consistently higher than those of unsterilized eggs.

Values showing statistically significant difference in color in each group of eggs are indicated with different superscript letters $\mathrm{a}, \mathrm{b}, \mathrm{c}, \mathrm{d}$, or e $(P<0.05)$. Positive and negative values in a (redness) are indicated by red and green, respectively, while positive and negative values in b (yellowness) are indicated by yellow and blue, respectively.

The color from egg yolk affects the acceptability of many food products. Therefore, customers may not accept discoloration and color changes in food products due to processing, considered as a decrement of egg quality [18]. Both the egg white and yolk contain riboflavin, which is a carotenoid pigment making the liquid whole eggs appear yellow and plays an important role in antioxidation as well. Egg white contains mostly proteins but with only a small amount of riboflavin and is therefore pale yellow in color. In our study, we speculate that the color of liquid whole eggs changes over time mainly because of changes in pigment, fat, and protein contents. Egg yolk also contains a high fat content. During storage, fat oxidation and rancidity cause the degree of yellowness of egg yolk to gradually decrease [5]. Furthermore, the formation of colloids from protein and fat is advantageous for light transmission but may also diminish the yellowness of egg yolk. 
TABLE 2: Gel strength of UHT-pasteurized and unsterilized liquid whole eggs.

\begin{tabular}{lcc}
\hline Storage time (week) & Unsterilized liquid whole eggs $\left(\mathrm{g} / \mathrm{cm}^{2}\right)$ & UHT-pasteurized liquid whole eggs $\left(\mathrm{g} / \mathrm{cm}^{2}\right)$ \\
\hline 1 & 1345.27 & 1504.39 \\
2 & 1348.14 & 1459.54 \\
3 & 1330.65 & 1333.79 \\
4 & 1308.94 & 1315.14 \\
5 & 1099.09 & 1246.23 \\
\hline
\end{tabular}

TABLE 3: Color of UHT-pasteurized and unsterilized liquid whole eggs.

\begin{tabular}{lcccccc}
\hline \multirow{2}{*}{ Storage time (week) } & \multicolumn{2}{c}{ UHT-pasteurized liquid whole egg } & \multicolumn{2}{c}{ Unsterilized liquid whole egg } \\
& L (lightness) & a (redness) & b (yellowness) & L (lightness) & a (redness) & b (yellowness) \\
\hline 1 & $65.4 \pm 1.18^{\mathrm{c}}$ & $14.2 \pm 0.41^{\mathrm{d}}$ & $41.6 \pm 1.11^{\mathrm{a}}$ & $64.9 \pm 0.07^{\mathrm{ab}}$ & $15.4 \pm 0.00^{\mathrm{e}}$ & $46.3 \pm 0.24^{\mathrm{d}}$ \\
2 & $66.1 \pm 0.04^{\mathrm{d}}$ & $13.4 \pm 0.06^{\mathrm{c}}$ & $44.0 \pm 0.11^{\mathrm{b}}$ & $67.7 \pm 0.02^{\mathrm{d}}$ & $14.9 \pm 0.05^{\mathrm{d}}$ & $42.8 \pm 0.17^{\mathrm{c}}$ \\
3 & $65.0 \pm 1.12^{\mathrm{c}}$ & $13.1 \pm 1.11^{\mathrm{c}}$ & $41.6 \pm 1.15^{\mathrm{a}}$ & $66.3 \pm 0.07^{\mathrm{c}}$ & $13.7 \pm 0.00^{\mathrm{c}}$ & $41.5 \pm 0.05^{\mathrm{b}}$ \\
4 & $64.9 \pm 0.00^{\mathrm{b}}$ & $10.6 \pm 4.51^{\mathrm{b}}$ & $41.4 \pm 1.59^{\mathrm{a}}$ & $65.3 \pm 0.04^{\mathrm{bc}}$ & $12.9 \pm 0.06^{\mathrm{b}}$ & $40.9 \pm 0.05^{\mathrm{b}}$ \\
5 & $63.3 \pm 0.02^{\mathrm{a}}$ & $8.0 \pm 0.88^{\mathrm{a}}$ & $41.4 \pm 0.28^{\mathrm{a}}$ & $63.4 \pm 0.24^{\mathrm{a}}$ & $12.3 \pm 0.28^{\mathrm{a}}$ & $38.9 \pm 0.05^{\mathrm{a}}$ \\
\hline
\end{tabular}

3.7. Soluble Protein Contents of the UHT-Pasteurized and Unsterilized Liquid Whole Eggs. Studies have shown correlations between the functionality of the egg proteins and the soluble protein contents of the liquid whole eggs $[4,44,45]$. Therefore, a reduction in the soluble protein contents suggests a potentially decreased functionality of egg proteins. The soluble protein contents of both the UHT-pasteurized and unsterilized liquid whole eggs increased in the first three weeks of storage, reaching the highest values of 0.4699 and 0.3355 , respectively, in week 3 ; then deceased in weeks 4 and 5 (Table 4). The soluble protein contents of UHT-pasteurized and unsterilized liquid whole eggs showed the lowest values of 0.2656 in week 1 and 0.1529 in week 5 of storage, respectively. The soluble protein contents of both the UHT-pasteurized and unsterilized liquid whole eggs showed significant difference across the entire timepoints of the five weeks of storage $(P<0.05)$, with the UHT-pasteurized liquid whole eggs showing the higher soluble protein contents than that of the unsterilized liquid whole eggs. These results indicated that the UHT pasteurization increased the soluble protein contents of liquid whole eggs.

Changes in the soluble protein contents of the liquid whole eggs reflect changes of protein structure during storage. The increase in the soluble protein contents might be caused by the disassembly of HDL in the egg yolk and the breakdown of egg yolk proteins into subunits of smaller molecular weight, which are released into the egg white and thereby increasing the soluble proteins content of the eggs [46]. Several proteins in protein-fat compounds also promote protein dissolution. However, the decrease of soluble protein contents with storage time could be caused by the charge effects between dissolved and soluble proteins, the combination of proteins and fat, or the action of crosslinking [47]. In our study, the UHT-sterilized liquid whole eggs were hardly affected by microorganisms and the change in protein structure was also slow (Table 4). Therefore, the UHTpasteurized eggs are potentially more suitable and appropriate for long-term storage.
3.8. Correlation Analysis of the Physical and Chemical Properties of UHT-Pasteurized and Unsterilized Liquid Whole Eggs. Results of the correlation analysis showed that the EAI of UHT-pasteurized liquid whole eggs was negatively correlated with the soluble protein content $(r=-0.884$, $P<0.01$ ), while being positively correlated with the gel strength $(r=0.732, P<0.01)$ (Table 5$)$. Significantly positive correlations were also revealed between ESI and the soluble protein content and between foam stability and the soluble protein content $(r=0.904$ and $0.836, P<0.01)$, respectively. Foaming ability was negatively correlated with thiol content and viscosity $(r=0.760$ and $0.848, P<0.01)$, respectively, but positively correlated with gel strength $(r=0.658, P<0.01)$. Viscosity was positively correlated with thiol content $(r=0.697, P<0.01)$ and negatively correlated with gel strength $(r=-0.722, P<0.01)$, while the thiol content and gel strength showed a significantly negative correlation $(r=-0.888, P<0.01)$.

Results of the correlation analysis showed that the EAI of unsterilized liquid whole eggs was negatively correlated with ESI $(r=-0.791, P<0.01)$ (Table 5 ), while being positively correlated with foaming ability, thiol content, and solid content $(r=0.735,0.842$, and $0.906, P<0.01)$, respectively. The ESI was negatively correlated with solid content $(r=-0.722, P<0.01)$ and thiol content $(r=-0.595, P<0.05)$ but positively correlated with the soluble protein content $(r=0.613, P<0.05)$. There was a negative correlation between foaming ability and foam stability $(r=-0.754$, $P<0.01)$ and a negative correlation between ESI and thiol content $(r=-0.595, P<0.05)$, solid content $(r=-0.722$, $P<0.01)$, and gel strength $(r=-0.186, P<0.05)$, respectively. Negative correlations were also detected between foam stability and viscosity, gel strength, and soluble protein content $(r=-0.895,-0.86$, and $-0.782, P<0.01)$, respectively. Viscosity was positively correlated with gel strength $(r=0.755$, $P<0.01)$ and the soluble protein content $(r=0.845, P<0.01)$, while the gel strength and the soluble protein content were positively correlated $(r=0.593, P<0.05)$. 
TABLE 4: Soluble protein contents of UHT-pasteurized and unsterilized liquid whole eggs. Values showing statistically significant difference in soluble protein contents in each group of eggs are indicated with different superscript letters $\mathrm{a}, \mathrm{b}, \mathrm{c}, \mathrm{d}$, or e $(P<0.05)$.

\begin{tabular}{lcc}
\hline Storage time (week) & UHT-pasteurized liquid whole eggs & Unsterilized liquid whole eggs \\
\hline 1 & $0.2656 \pm 0.002^{\mathrm{a}}$ & $0.1942 \pm 0.005^{\mathrm{b}}$ \\
2 & $0.3920 \pm 0.013^{\mathrm{d}}$ & $0.2499 \pm 0.014^{\mathrm{d}}$ \\
3 & $0.4699 \pm 0.006^{\mathrm{e}}$ & $0.3355 \pm 0.019^{\mathrm{e}}$ \\
4 & $0.3690 \pm 0.065^{\mathrm{c}}$ & $0.2144 \pm 0.026^{\mathrm{c}}$ \\
5 & $0.3464 \pm 0.102^{\mathrm{b}}$ & $0.1529 \pm 0.045^{\mathrm{a}}$ \\
\hline
\end{tabular}

TABLE 5: Correlation analysis of the physical and chemical properties of unsterilized and UHT-pasteurized liquid whole eggs.

\begin{tabular}{|c|c|c|c|c|c|c|c|c|c|}
\hline & EAI & ESI & $\begin{array}{c}\text { Foaming } \\
\text { ability }\end{array}$ & $\begin{array}{c}\text { Foaming } \\
\text { stability }\end{array}$ & Viscosity & $\begin{array}{c}\text { Thiol } \\
\text { content }\end{array}$ & $\begin{array}{c}\text { Solid } \\
\text { content }\end{array}$ & $\begin{array}{c}\text { Gel } \\
\text { strength }\end{array}$ & $\begin{array}{c}\text { Soluble protein } \\
\text { content }\end{array}$ \\
\hline EAI & 1 & & & & & & & & \\
\hline ESI & $\begin{array}{l}-0.791^{* *} \\
-0.978^{*}\end{array}$ & 1 & & & & & & & \\
\hline Foaming ability & $\begin{array}{c}0.735^{* *} \\
0.095\end{array}$ & $\begin{array}{l}-0.272 \\
-0.077\end{array}$ & 1 & & & & & & \\
\hline Foaming stability & $\begin{array}{c}-0.455 \\
-0.760^{*}\end{array}$ & $\begin{array}{c}-0.058 \\
0.835^{* *} \\
\end{array}$ & $\begin{array}{c}-0.754^{* *} \\
0.174 \\
\end{array}$ & 1 & & & & & \\
\hline Viscosity & $\begin{array}{c}0.107 \\
-0.293\end{array}$ & $\begin{array}{l}0.326 \\
0.226\end{array}$ & $\begin{array}{c}0.511 \\
-0.848^{* *}\end{array}$ & $\begin{array}{c}-0.895^{* *} \\
-0.161\end{array}$ & 1 & & & & \\
\hline Thiol content & $\begin{array}{c}0.842^{* *} \\
-0.451 \\
\end{array}$ & $\begin{array}{c}-0.595^{*} \\
0.529^{*}\end{array}$ & $\begin{array}{c}0.820^{* *} \\
-0.760^{* *} \\
\end{array}$ & $\begin{array}{c}-0.473 \\
0.301 \\
\end{array}$ & $\begin{array}{c}0.087 \\
0.697^{* *} \\
\end{array}$ & 1 & & & \\
\hline Solid content & $\begin{array}{c}0.906^{* *} \\
0.162\end{array}$ & $\begin{array}{c}-0.722^{* *} \\
-0.033\end{array}$ & $\begin{array}{c}0.751^{* *} \\
0.303\end{array}$ & $\begin{array}{c}-0.343 \\
0.198 \\
\end{array}$ & $\begin{array}{l}-0.042 \\
-0.392 \\
\end{array}$ & $\begin{array}{c}0.966^{* *} \\
0.027\end{array}$ & 1 & & \\
\hline Gel strength & $\begin{array}{c}0.603^{*} \\
0.732^{* *} \\
\end{array}$ & $\begin{array}{c}-0.186 \\
-0.752^{*} \\
\end{array}$ & $\begin{array}{c}0.620^{*} \\
0.658^{* *}\end{array}$ & $\begin{array}{c}-0.860^{* *} \\
-0.529 \\
\end{array}$ & $\begin{array}{c}0.775^{* *} \\
-0.722^{* *} \\
\end{array}$ & $\begin{array}{c}0.339 \\
-0.888^{* *} \\
\end{array}$ & $\begin{array}{l}0.319 \\
0.083 \\
\end{array}$ & 1 & \\
\hline $\begin{array}{l}\text { Soluble protein } \\
\text { content }\end{array}$ & $\begin{array}{c}-0.163 \\
-0.884^{*}\end{array}$ & $\begin{array}{c}0.613^{*} \\
0.904^{* *}\end{array}$ & $\begin{array}{l}0.355 \\
0.333\end{array}$ & $\begin{array}{c}-0.782^{* *} \\
0.836^{* *}\end{array}$ & $\begin{array}{c}0.845^{* *} \\
-0.142\end{array}$ & $\begin{array}{c}-0.106 \\
0.163\end{array}$ & $\begin{array}{c}-0.262 \\
0.022\end{array}$ & $\begin{array}{l}0.593^{*} \\
-0.412\end{array}$ & 1 \\
\hline
\end{tabular}

${ }^{*}$ and ${ }^{* *}$ indicate $P<0.05$ and $P<0.01$, respectively. The correlation coefficient values $r$ for the unsterilized and UHT-pasteurized liquid eggs are given on the top and at the bottom in each pair of $r$ values, respectively.

These results showed that the correlations among various processing characteristics changed greatly after the liquid whole eggs were treated with the UHT pasteurization (Table 5). For example, the negative correlation between foaming stability and emulsification stability became significantly positive correlation. Changes from positive correlation to negative correlation were also observed between viscosity and foaming ability, emulsification ability, and gel strength, respectively, and between gel strength and soluble protein content. The correlations between thiol content and most of the processing characteristics, except for viscosity and solid content, changed between positive and negative correlations. This is probably due to the effect of thiol content on the other processing characteristics after the liquid whole eggs are treated with UHT pasteurization. We further speculate that the high temperatures of the UHT pasteurization change the protein structures, reduce the number of microorganisms, and alter the $\mathrm{pH}$ values in the liquid whole eggs, subsequently causing the changes between positive and negative correlations among various processing characteristics. Further studies are necessary to confirm and verify these observations.

\section{Conclusions}

We investigated the effects of UHT pasteurization on the liquid whole eggs by comparing several processing characteristics between the UHT-pasteurized and unsterilized liquid whole eggs. The emulsifying properties of sterilized eggs were initially low and further decreased with storage time. The ESI of UHT-pasteurized liquid whole eggs was higher than that of unsterilized eggs and increased by $21.87 \%$ (from 7.850 to 9.567 ) before decreasing. The foaming ability of UHT-pasteurized and unsterilized eggs increased by $33.38 \%$ and $15.48 \%$, respectively, while foam stability increased in the former. The viscosity, gel strength, and soluble protein content were higher in UHT-pasteurized liquid whole eggs than in unsterilized eggs and increased with prolonged time of storage. These results indicate that UHT pasteurization is a low-cost, safe, and highly efficient method for enhancing the shelf life of liquid whole eggs while preserving and improving many of the functional properties, which can increase their nutritional values, appeal to consumers, and expand their uses in the food industry. This study also demonstrates the feasibility and advantages of 
using UHT pasteurization in processing the liquid whole eggs in comparison to the conventional methods of sterilization.

\section{Data Availability}

The data used to support the findings of this study are available from the corresponding authors upon request.

\section{Conflicts of Interest}

The authors declare that they have no conflicts of interest.

\section{Authors' Contributions}

Tong Liu, Bo Lv, and Weixuan Zhao contributed equally to this work.

\section{Acknowledgments}

This work was funded by the National Key Research and Development Program of China (2018YFD0400304).

\section{References}

[1] X. Wang, S. Wu, H. Zhang, H. Yue, G. Qi, and J. Li, "Effect of dietary protein sources and storage temperatures on egg internal quality of stored shell eggs," Animal Nutrition, vol. 1, no. 4, pp. 299-304, 2015.

[2] H. D. Belitz, W. Grosch, and P. Schieberle, Food Chemistry, Springer Science and Business Media, Berlin, Germany, 4th edition, 2009.

[3] S. R. S. Dev, G. S. V. Raghavan, and Y. Gariepy, "Dielectric properties of egg components and microwave heating for inshell pasteurization of eggs," Journal of Food Engineering, vol. 86, no. 2, pp. 207-214, 2008.

[4] P. L. Dawson and R. Martinez-Dawson, "Using response surface analysis to optimize the quality of ultrapasteurized liquid whole egg," Poultry Science, vol. 77, no. 3, pp. 468-474, 1998.

[5] M. Koç, B. Koç, G. Susyal, M. Sakin Yilmazer, F. Kaymak Ertekin, and N. Bağdatloğlu, "Functional and physicochemical properties of whole egg powder: effect of spray drying conditions," Journal of Food Science and Technology, vol. 48, no. 2, pp. 141-149, 2011.

[6] Z. Akkouche, K. Madani, and L. Aissat, Effect of Heat on Egg White Proteins, Intech Open Access Publisher, London, UK, 2012.

[7] L. Garcia-Gonzalez, A. H. Geeraerd, K. Elst, L. Van Ginneken, J. F. Van Impe, and F. Devlieghere, "Inactivation of naturally occurring microorganisms in liquid whole egg using high pressure carbon dioxide processing as an alternative to heat pasteurization," The Journal of Supercritical Fluids, vol. 51, no. 1, pp. 74-82, 2009.

[8] N. M. Mitchell, J. R. Johnson, B. Johnston, R. Curtiss III, and M. Mellata, "Zoonotic potential of Escherichia coli isolates from retail chicken meat products and eggs," Applied and Environmental Microbiology, vol. 81, no. 3, pp. 1177-1187, 2015.

[9] Y. Wang, K. Liang, P. Liu, J. Qiu, X. Zhao, and D. Zhu, "Research status of egg sterilization technology and equipment," Food Science and Technology, vol. 44, pp. 79-85, 2019.
[10] R. Marco-Molés, M. A. Rojas-Graü, I. Hernando, I. PérezMunuera, R. Soliva-Fortuny, and O. Martín-Belloso, "Physical and structural changes in liquid whole egg treated with highintensity pulsed electric fields," Journal of Food Science, vol. 76, no. 2, pp. C257-C264, 2011.

[11] F. Baron, S. Jan, and R. Jeantet, "Qualit_e microbiologique des ovoproduits," in Sciences et Technologie de L'oeuf: de L'oeuf Aux Ovoproduits, F. Nau, C. Gu_erin-Dubiard, F. Baron, and J. L. Thapon, Eds., pp. 321-349, Lavoisier Tec \& Doc, Paris, Italy, 2010.

[12] V. Falguera, J. Pagán, S. Garza, A. Garvín, and A. Ibarz, "Ultraviolet processing of liquid food: a review," Food Research International, vol. 44, no. 6, pp. 1580-1588, 2011.

[13] G. Saldaña, S. Monfort, S. Condón, J. Raso, and I. Á \& ónt, "Effect of temperature, $\mathrm{pH}$ and presence of nisin on inactivation of Salmonella typhimurium and Escherichia coli O157: H7 by pulsed electric fields," Food Research International, vol. 45, no. 2, pp. 1080-1086, 2012.

[14] S. Monfort, G. Saldaña, S. Condón, J. Raso, and I. Á \& óna, "Inactivation of Salmonella spp. in liquid whole egg using pulsed electric fields, heat, and additives," Food Microbiology, vol. 30, no. 2, pp. 393-399, 2012.

[15] P. M. de Souza, A. Briviba, A. Müller, A. Fernández, and M. Stah1, "Cyto-genotoxic and oxidative effects of a continuous UV-C treatment of liquid whole egg products," Food Chemistry, vol. 138, no. 2-3, pp. 1682-1688, 2013.

[16] D. J. Geveke, J. B. Gurtler, D. R. Jones, and A. B. W. Bigley, "Inactivation of Salmonella in shell eggs by hot water immersion and its effect on quality," Journal of Food Science, vol. 81, no. 3, pp. M709-M714, 2016.

[17] S. Mukhopadhyay and R. Ramaswamy, "Application of emerging technologies to control Salmonella in foods: a review," Food Research International, vol. 45, no. 2, pp. 666-677, 2012.

[18] P. M. de Souza and A. Fernández, "Effects of UV-C on physicochemical quality attributes and Salmonella enteritidis inactivation in liquid egg products," Food Control, vol. 22, no. 8, pp. 1385-1392, 2011.

[19] P. M. de Souza, A. Müller, A. Beniaich et al., "Functional properties and nutritional composition of liquid egg products treated in a coiled tube UV-C reactor," Innovative Food Science \& Emerging Technologies, vol. 32, pp. 156-164, 2015.

[20] S. Monfort, S. Ramos, N. Meneses, D. Knorr, J. Raso, and I. Á \& res, "Design and evaluation of a high hydrostatic pressure combined process for pasteurization of liquid whole egg," Innovative Food Science \& Emerging Technologies, vol. 14, pp. 1-10, 2012.

[21] N. Hermawan, G. A. Evrendilek, W. R. Dantzer, Q. H. Zhang, and E. R. Richter, "Pulsed electric field treatment of liquid whole egg inoculated with Salmonella enteritidis," Journal of Food Safety, vol. 24, no. 1, pp. 71-85, 2004.

[22] D. J. Geveke, A. B. W. Bigley, and C. D. Brunkhorst, "Pasteurization of shell eggs using radio frequency heating," Journal of Food Engineering, vol. 193, pp. 53-57, 2016.

[23] K. Baba, T. Kajiwara, S. Watanabe, S. Katsuki, R. Sasahara, and K. Inoue, "Low-temperature pasteurization of liquid whole egg using intense pulsed electric fields," Electronics and Communications in Japan, vol. 101, no. 2, pp. 87-94, 2017.

[24] L. G. Phillips, Z. Haque, and J. E. Kinsella, "A method for the measurement of foam formation and stability," Journal of Food Science, vol. 52, no. 4, pp. 1074-1077, 1987.

[25] W. Zhao, R. J. Yang, Y. L. Tang, and R. R. Lu, "Combined effects of heat and PEF on microbial inactivation and quality 
of liquid whole egg whites," International Journal of Food Engineering, vol. 3, no. 4, pp. 1556-3758, 2007.

[26] A. C. Sánchez-Gimeno, A. Vercet, and P. López-Buesa, "Studies of ovalbumin gelation in the presence of carrageenans and after manothermosonication treatments," Innovative Food Science \& Emerging Technologies, vol. 7, no. 4, pp. 270-274, 2006.

[27] N. Kassis, S. R. Drake, S. K. Beamer, K. E. Matak, and J. Jaczynski, "Development of nutraceutical egg products with omega-3-rich oils," LWT-Food Science and Technology, vol. 43 , no. 5, pp. 777-783, 2010.

[28] K. Shimada and J. C. Cheftel, "Determination of sulfhydryl groups and disulfide bonds in heat-induced gels of soy protein isolate," Journal of Agricultural and Food Chemistry, vol. 36, no. 1, pp. 147-153, 1988.

[29] M. Hamid-Samimi, K. R. Swartzel, and H. R. Ball, "Flow behavior of liquid whole egg during thermal treatments," Journal of Food Science, vol. 49, no. 1, pp. 132-136, 1984.

[30] A. Alleoni and A. Antunes, "Albumen foam stability and s-ovalbumin contents in eggs coated with whey protein concentrate," Revista Brasileira de Ciência Avícola, vol. 6, no. 2, pp. 105-110, 2004.

[31] N. A. Ali, S. H. Ahmed, E. A. Mohamed, I. A. Mohamed Ahmed, and E. Babiker, "Effect of transglutaminase crosslinking on the functional properties as a function of $\mathrm{NaCl}$ concentration of legumes protein isolate," International Journal of Biological Life Sciences, vol. 7, pp. 8-13, 2011.

[32] L. Du, A. Prokop, and R. D. Tanner, "Effect of denaturation by preheating on the foam fractionation behavior of ovalbumin," Journal of Colloid and Interface Science, vol. 248, no. 2, pp. 487-492, 2002.

[33] C.-Y. Ma, M. R. Sahasrabudhe, L. M. Poste, V. R. Harwalkar, J. R. Chambers, and K. P. J. O’Hara, “Gamma irradiation of shell eggs. Internal and sensory quality, physicochemical characteristics, and functional properties," Canadian Institute of Food Science and Technology Journal, vol. 23, no. 4-5, pp. 226-232, 1990.

[34] P. M. de Souza and A. Fernández, "Consumer acceptance of UV-C treated liquid egg products and preparations with UV$\mathrm{C}$ treated eggs," Innovative Food Science \& Emerging Technologies, vol. 14, pp. 107-114, 2012.

[35] S. Monfort, P. Mañas, S. Condón, J. Raso, and I. Álvarez, "Physicochemical and functional properties of liquid whole egg treated by the application of pulsed electric fields followed by heat in the presence of triethyl citrate," Food Research International, vol. 48, no. 2, pp. 484-490, 2012.

[36] M. L. Calderón-Miranda, G. V. Barbosa-Cánovas, and B. G. Swanson, "Inactivation of Listeria innocua in liquid whole egg by pulsed electric fields and nisin," International Journal of Food Microbiology, vol. 51, no. 1, pp. 7-17, 1999.

[37] L. Qiao, X. Yang, and Y. Yang, "Effect of heat-treatment on the functional properties of liquid whole egg," Science and Technology of Food Industry, vol. 32, pp. 134-137, 2011.

[38] W. Yan, X. Su, and Y. Yang, "Study on the properties of composition of egg yolk," Science and Technology of Food Industry, vol. 31, pp. 158-160, 2010.

[39] F. Guilmineau and U. Kulozik, "Impact of a thermal treatment on the emulsifying properties of egg yolk. Part 1: effect of the heating time," Food Hydrocolloids, vol. 20, no. 8, pp. 11051113, 2006.

[40] I. van der Plancken, A. van Loey, and M. E. Hendrickx, "Combined effect of high pressure and temperature on selected properties of egg white proteins," Innovative Food Science \& Emerging Technologies, vol. 6, no. 1, pp. 11-20, 2005.
[41] V. Kiosseoglou and A. Paraskevopoulou, "Molecular interactions in gels prepared with egg yolk and its fractions," Food Hydrocolloids, vol. 19, no. 3, pp. 527-532, 2005.

[42] G. Campbell and E. Mougeot, "Creation and characterisation of aerated food products," Trends in Food Science \& Technology, vol. 10, no. 9, pp. 283-296, 1999.

[43] N. Müller-Fischer and E. J. Windhab, "Influence of process parameters on microstructure of food foam whipped in a rotor-stator device within a wide static pressure range," Colloids and Surfaces A: Physicochemical and Engineering Aspects, vol. 263, no. 1-3, pp. 353-362, 2005.

[44] T. J. Herald and D. M. Smith, "Functional properties and composition of liquid whole egg proteins as influenced by pasteurization and frozen storage," Poultry Science, vol. 68, no. 11, pp. 1461-1469, 1989.

[45] K. R. Swartzel, H. R. Ball, and M. Hamid-Samimi, "Method for the ultrapasteurization of liquid whole egg products," U.S. Patent, North Carolina State University, Raleigh, NC, USA, 1986.

[46] F. Ferreira Machado, J. S. R. Coimbra, E. E. Garcia Rojas, L. A. Minim, F. C. Oliveira, and R. D. C. S. Sousa, "Solubility and density of egg white proteins: effect of $\mathrm{pH}$ and saline concentration," LWT-Food Science and Technology, vol. 40, no. 7, pp. 1304-1307, 2007.

[47] R. D. C. S. Sousa, J. S. R. Coimbra, E. E. Garcia Rojas, L. A. Minim, F. C. Oliveira, and V. P. R. Minim, "Effect of pH and salt concentration on the solubility and density of egg yolk and plasma egg yolk," LWT-Food Science and Technology, vol. 40, no. 7, pp. 1253-1258, 2007. 


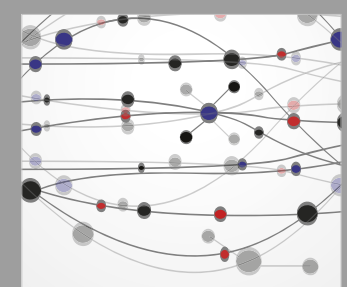

The Scientific World Journal
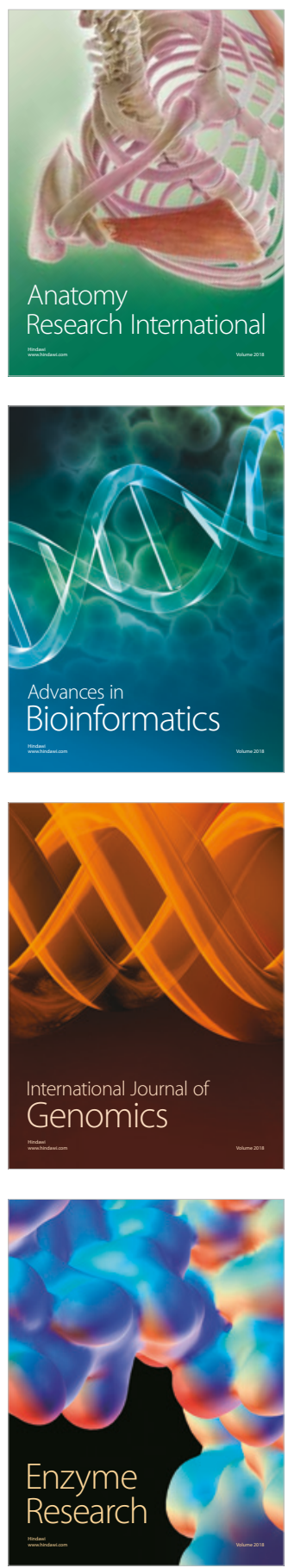
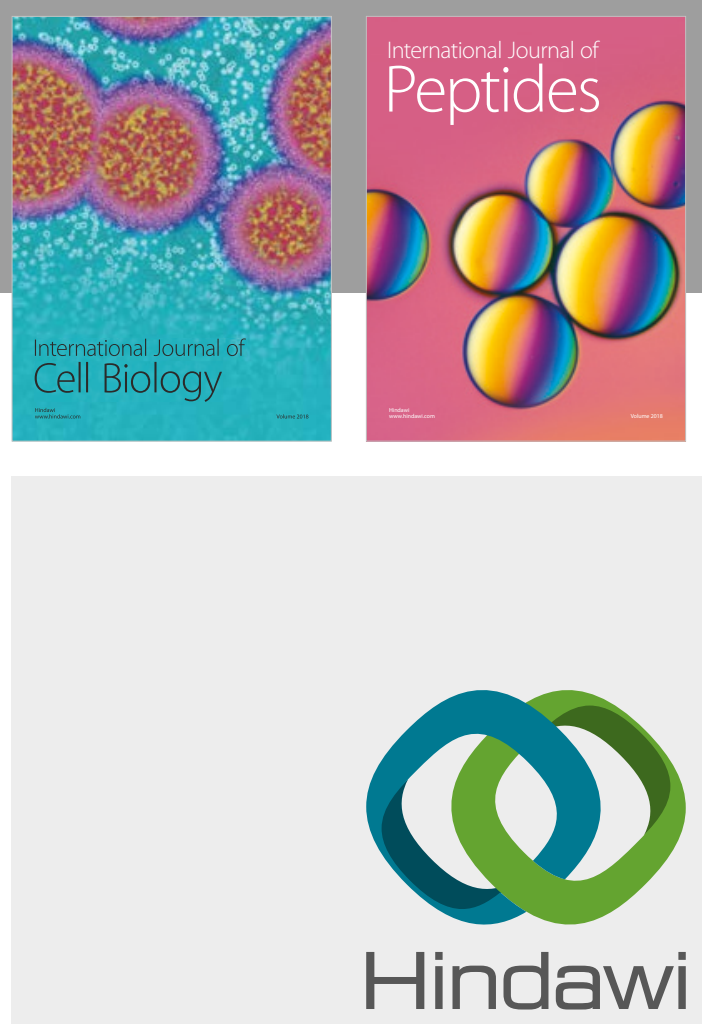

Submit your manuscripts at

www.hindawi.com
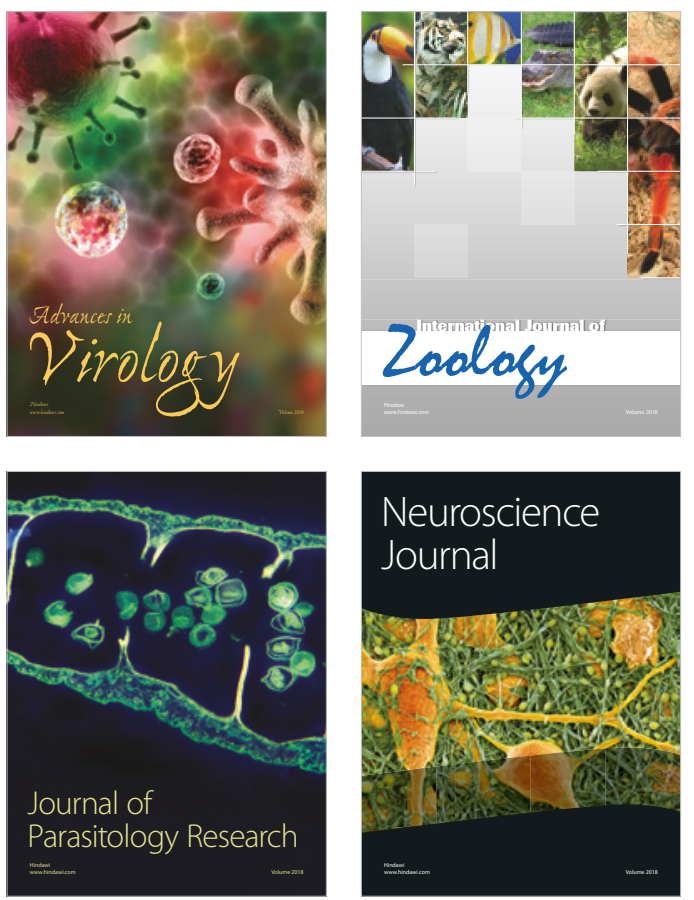
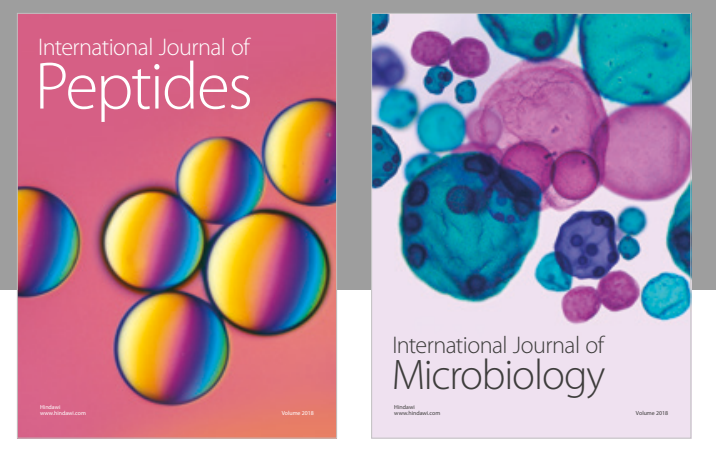

nternational Journal of Microbiology
Journal of
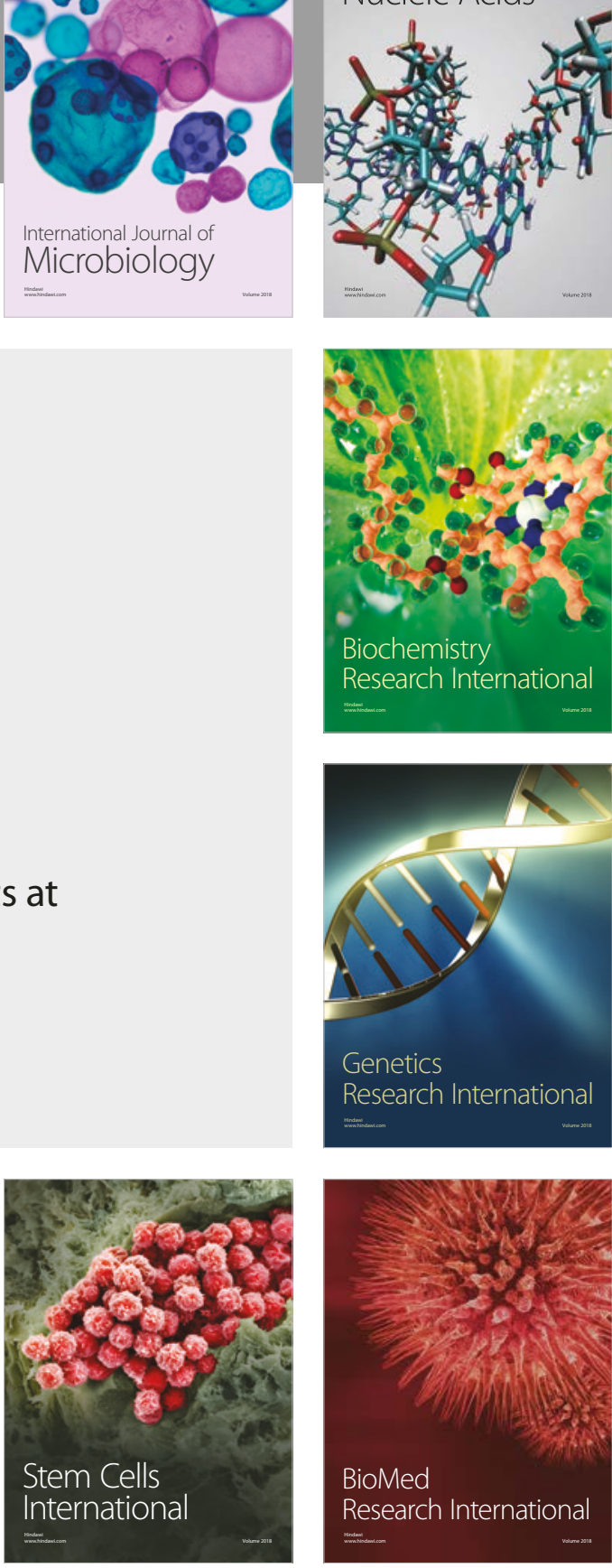
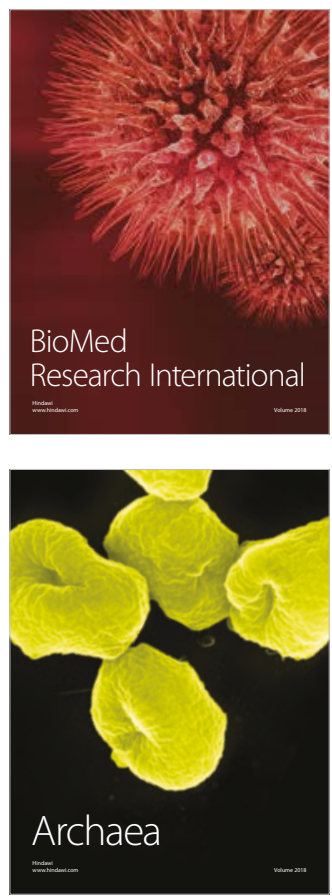